\title{
TEATRO DE BONECOS E MEIO AMBIENTE: INTEGRANDO CIÊNCIA E ARTE
}

Vanessa Oliveira Fernandes Câmara ${ }^{1}$

Maria Cristina Basílio Crispim²

Gil Dutra Furtado 3

Resumo: Cada vez mais a Educação Ambiental precisa inovar em suas estratégias educativas para responder os desafios da sustentabilidade. Logo, o teatro de bonecos representa um recurso pedagógico que pode ser facilmente utilizado em espaços não formais. Cada boneco possui um potencial diferenciado frente às técnicas teatrais amplamente diversificadas. Neste sentido, o presente estudo objetiva apresentar algumas variações de fantoches experimentados e suas possibilidades lúdicas para atividades educativas contextualizadas com o meio ambiente. Para tanto, foram confeccionados os fantoches utilizados e elaborados roteiros teatrais. Verificou-se que o fantoche é uma excelente ferramenta lúdica e cada modelo possui características próprias que podem ser adaptadas para a sensibilização ambiental de crianças e adultos.

Palavras-chave: Fantoches; Meio Ambiente; Artes

\footnotetext{
1 Universidade Federal da Paraíba; Instituto Federal de Educação, Ciência e Tecnologia da Paraíba. Email: vanessa.oliveirafernandes@gmail.com

2 Universidade Federal da Paraíba. E-mail: ccrispim@hotmail.com

3 Universidade Federal da Paraíba. E-mail: gdfurtado@hotmail.com
}

Revbea, São Paulo, V. 12, № 5: 73-83, 2017.

revista brasileira educação ambiental 


\section{Introdução}

Atividades educativas, devem mudar em muitos aspectos as suas ferramentas didáticas, para aumentar a motivação dos educandos para o aprendizado.

Neste sentido, o uso de recursos estimuladores de processos cognitivos é fundamental para fortalecer 0 ensino contextualizado com temas transversais, tais como as ciências ambientais necessitam. Logo, a realização de atividades lúdicas, experimentais e criativas podem conduzir positivamente ao aprender fazendo, pensando, brincando e construindo o próprio conhecimento.

A arte através do teatro de bonecos constitui uma prática que vem sendo difundida no campo da Educação Ambiental. Embora, muitas vezes esteja restrita apenas no ambiente escolar e à arte com reaproveitamento de resíduos, os fantoches possuem uma série de possibilidades na condição de ferramenta lúdica educativa em diferentes espaços, não apenas no escolar.

Verifica-se que, atualmente, considerável parte dos educadores não formais apresentam dificuldades para produzir e buscar estratégias educativas dinâmicas voltadas para a sensibilização ambiental. O que consequentemente, compromete $O$ ato de aprender e os resultados esperados com a Educação Ambiental (EA), por não trazer alternativas dinâmicas, que aumentem a motivação dos aprendizes. Para tanto, as reflexões abordadas neste estudo objetivam a socialização da experiência realizada no Programa de Pós graduação em Desenvolvimento e Meio Ambiente (PRODEMA) da Universidade Federal da Paraíba (UFPB), que é parte integrante dos resultados da pesquisa de mestrado intitulada "Teatro de bonecos como ferramenta de sensibilização ambiental em Unidades de conservação". Para alcançar tais resultados utilizou-se a revisão bibliográfica como técnica de pesquisa qualitativa, bem como a confecção de bonecos e a preparação de cenários para apresentações teatrais.

Este estudo também representa a consolidação de que é possível o uso do teatro de bonecos na EA em espaços educativos não formais, e as unidades de conservação por si constituem espaços de aprendizagem e construção de seres humanos integrais, sociais e participativos.

Assim, explora-se aqui, origem, conceitos, tipos e potenciais lúdicos dos bonecos utilizados na pesquisa citada.

\section{Surgimento dos bonecos}

A linguagem teatral era bastante utilizada pelo povos primitivos em rituais e encenações religiosas, tornou-se arte no momento em que a civilização grega organizou-se para preparar apresentações bem elaboradas. Sabe-se que desde os primórdios o teatro é utilizado para divertir e dramatizar situações diversas. 
Atividades como interpretações, improvisações e dramatizações com textos jornalísticos, artigos de revistas, temas oferecidos, poesias, objetos, máscaras, imagens, sons e situações do cotidiano, poderão permear o trabalho com diferentes temáticas. O fato é que existem diversas maneiras de desenvolver a arte teatral, nesse estudo, dá-se ênfase à arte do teatro de bonecos ou fantoches.

Nesse sentido, dramatizar permite ao indivíduo estabelecer relações consigo mesmo e com os outros. Ensina a ouvir, esperar e a respeitar as diferentes opiniões e, dessa forma, ir-se integrando ao grupo. É uma atividade socializadora que dá liberdade para o convívio democrático, estabelecendo uma organização estética. Telles $(2013$, p.87) explicou que o "acesso à apresentações teatrais, à literatura, a exercícios gestuais, mímicas e a jogos corporais deverá fazer parte do universo das artes teatrais, uma vez que permite a aprendizagem e a elaboração de um juízo crítico".

Segundo Ladeira e Caldas (1998, p. 10), o "teatro de bonecos é uma expressão teatral que caracteriza as encenações realizadas com fantoches, marionetes e/ou bonecos. A arte milenar do teatro de bonecos" consegue encantar crianças e até mesmo adultos e "é uma das mais antigas maneiras de diversão entre a humanidade. Registros dessa expressão artística existem desde a Pré-História": Segundo esses autores,

o teatro de bonecos tem sua origem na mais remota Antiguidade. Acredita-se que na Pré-História os homens se encantavam com suas sombras movendo-se nas paredes das cavernas. Nessa época, as mães teriam desenvolvido o teatro de dedos, projetando, com as mãos, sombras diversas nas paredes para distrair os filhos (p.10).

A origem do Teatro de Bonecos registrou-se no Oriente Antigo, havendo os relatos mais antigos na Índia, China e Indonésia. Devido ao comércio, através dos comerciantes, essas formas lúdicas de arte foram-se disseminando por toda a Europa, havendo relatos que esta ferramenta era usada para a evangelização das pessoas.. Contudo, com a chegada do Cristianismo, em destaque no período da Renascença, o Teatro de Bonecos tornou-se obsoleto, visto que a Igreja associava esta ação aos antigos ritos animistas, e assim proibia a sua encenação dentro dos templos. Com a proibição do teatro de bonecos, por parte da Igreja, foi substituído pelos espetáculos itinerantes, para os quais foi necessário reduzir o porte e formas para poderem circular melhor com suas representações, nos pequenos povoados da Europa (FANTINATO; RODRIGUES, 2004).

O surgimento do Teatro de Bonecos na América latina ocorreu no período dos grandes descobrimentos, em meados do século XVI, o que favoreceu a sua divulgação no mundo inteiro. Ainda no Renascimento eles são novamente aceites pelas igrejas, sendo realizados também nas residências e 
nas festas realizadas durante as feiras. O público passa a ser mais popular e 0 teatro de fantoches passa a ser mais satírico, impregnado de humor (LADEIRA; CALDAS, 1998).

Seguindo a evolução histórica, os bonecos foram-se alterando de acordo com as características de cada época. Assim, eles estão-se sempre adequando e adaptando, sempre assumindo novas formas. Essa modalidade teatral busca preservar um caráter nômade, ou seja, a caraterística itinerante ainda assegura a capacidade de encenar seus espetáculos não só nos teatros convencionais, mas também nas ruas, nas praias, igrejas, escolas e nos espaços ao ar livre (BLUMENTHAL, 2005).

Segundo Fantinato e Rodrigues (2004, s/p), depois da primeira guerra mundial, as marionetes, bonecos articulados movidos por fios, foram difundidos pelo mundo e introduzidos nas escolas, e no Brasil, os bonecos de fantoches iniciaram por ser utilizados em representações. Ainda segundo os autores, foi na região nordeste que o teatro de bonecos se destacou, principalmente no estado de Pernambuco, onde até os dias atuais é uma de suas maiores tradições, sendo esse teatro conhecido como "mamulengo", rico em situações cômicas e satíricas.

Observando a trajetória, o teatro de bonecos revela-se como um elo que faltava para auxiliar nos processos ensino-aprendizagem, pois os bonecos estão sendo utilizados desde a pré-história. Em cena, os bonecos tomam vida própria através das mãos do manipulador, contam histórias e transformam a vida numa magia que muitas vezes nos fazem sair da realidade pelo seu grande poder de sugestão. Todas as suas expressões se concentram nos movimentos e falas, e, atualmente, há uma diversidade de bonecos, variadas formas e cores, vários tipos de bonecos.

\section{Tipos de bonecos ${ }^{4}$}

Com o decorrer do tempo, os bonecos foram ganhando novas formas e atualmente encontram-se diferentes formas de confeccionar e manipular os bonecos. Cada um possui características específicas e exige uma linguagem dramática especial. Algumas tipologias de bonecos só se desenvolvem baseados em certas condições culturais e geográficas. Os principais tipos de bonecos são classificados pelo site POINTDAART (2004, s/p) da seguinte formar:

1) FANTOCHES - bonecos de mão ou de luva: Esse tipo possui corpo de tecido, vazio, que o manipulador veste na mão; ele encaixa os dedos na cabeça e nos braços para movimentálos. A figura é vista só da cintura para cima e geralmente não tem pernas. A cabeça pode ser feita de madeira, papier-maché,

\footnotetext{
${ }^{4}$ Este tópico foi extraído e adaptado de http://pointdarte.webnode.com.br/news/a-historia-doteatro-de-bonecos/, sendo devidamente citada a fonte nas referências.
}

Revbea, São Paulo, V. 12, № 5: 73-83, 2017. 
ou borracha, as mãos são de madeira ou de feltro. O modo de operação mais comum é usar o dedo indicador para a cabeça, e o polegar e o dedo máximo para os braços. Esse é o típico show de fantoches apresentado ao ar livre por toda a Europa. A vantagem do fantoche ou boneco de mão é a sua agilidade e rapidez; a limitação é seu tamanho reduzido e os movimentos de braços pouco eficientes.

2) BONECOS-DE-VARA: São figuras também manipuladas por baixo, mas de tamanho grande, sustentadas por uma vara que atravessa todo o corpo, até a cabeça. Outras varas mais finas podem ser usadas para movimentar as mãos e, se necessário, as pernas. Esse tipo de figura é tradicional nas ilhas indonésias de Java e Bali, onde são chamadas de wayang golek. Em geral, o boneco de vara é adequado a peças de ritmo lento e solene, mas são muitas as suas potencialidades e grande a sua variedade. Porém é muito exigente quanto ao número de manipuladores, exigindo sempre uma pessoa por boneco, e às vezes duas ou três para uma única figura.

3) MARIONETES-OU-BONECOS-DE-FIO: São figuras grandes controladas por cima. Normalmente são movimentadas por cordões ou fios que vão dos membros para uma cruzeta de controle na mão do manipulador. O movimento é feito por meio da inclinação ou oscilação da cruzeta de controle, mas os fios são também puxados um a um quando se deseja um determinado movimento. Uma marionete simples pode chegar a ter nove fios: um em cada perna, um em cada mão, um em cada ombro, um em cada orelha (para mexer a cabeça) e um na base da coluna, para fazer o boneco se inclinar. Efeitos mais detalhados podem exigir o dobro ou o triplo desse número. A manipulação de uma marionete de muitos fios é uma operação complexa que exige grande treinamento.

4) TEATRO-DE-SOMBRAS: Trata-se de um tipo especial de figura plana, utilizada para projetar sombras em um telão semitransparente. Podem ser recortadas em couro ou qualquer outro material opaco, como nos teatros tradicionais de Java, Bali e da Tailândia, além do tradicional "sombras chinesas" da Europa do século XVIII; nos teatros tradicionais da China, Índia, Turquia e Grécia, e em diversos grupos modernos da Europa, as figuras podem ser recortadas também em couro de peixe ou em outros materiais transparentes. Elas podem ser operadas por baixo, com varas, como no teatro javanês; com varas que ficam em ângulo reto com a tela, como nos teatros chinês e grego; ou por meio de cordões escondidos atrás dos bonecos como nas sombras chinesas. O teatro de sombras não precisa se limitar a figuras planas. Ele pode lançar mão também de figuras tridimensionais. 
Diante do exposto, é possível perceber que a criação de objetos que substituam o humano existe desde a antiguidade, os bonecos surgem da necessidade de representar simbolicamente algo ao outro e a si mesmo. Trazendo a exposição de algo internalizado. $O$ boneco pode substituir o real (SANTOS, 2006).

Neste estudo, utilizou-se a tipologia do Fantoche, por ser de fácil confecção e manipulação. Consistindo em um boneco animado diante de um público, tomando vida segundo o seu manipulador. Os fantoches podem ser criados/confeccionados a partir de modelos humanos, mas também é possível utilizar outras formas de vida, como animais e plantas para encenar histórias, ficando a cargo da criatividade do educador.

Um fantoche é um meio de expressão, possui função social e é um elemento de comunicação. Tem o poder de promover relações com o mundo externo e com outros seres vivos. Os fantoches são em si, estimuladores de diálogo. Através do teatro de fantoches, a aprendizagem ocorre facilmente. Ao serem propostas ressignificações mais elaboradas pelo educador, ele permeia os saberes já construídos com os novos saberes (SANTOS, 2006).

Atividades como o teatro de fantoches, promovem o lúdico, o imaginário e a interação com o conteúdo e com os outros, são verdadeiras experiências de aprendizagem, na qual o espaço de brincar se confunde com o espaço de aprender. Sendo, portanto, uma ferramenta com uso potencial na Educação Ambiental.

\section{Teatro de bonecos como ferramenta de Educação Ambiental}

Segundo Pereira $(2010$, p. 83$)$ a "vivência de práxis pedagógica inovadora, a partir da ludicidade, oportuniza mudanças significativas para o processo ensinar-aprender ciências naturais". Ou seja, o ensino centrado na ludicidade deve facilitar a vivência de momentos educativos, contribuindo para o despertar da consciência crítica-reflexiva, bem como o respeito às interrelações ser humano-natureza.

Nesse contexto, a vivência de atividades lúdicas contribui para o desenvolvimento do imaginário infantil, da criatividade e do pensamento lógico. Dessa maneira, permite a compreensão da natureza viva e seus limites. Sensibilizando e proporcionando uma experiência efetiva com os elementos da natureza (PEREIRA, 2010).

Utilizar o teatro de fantoches em atividades de EA é um modo de educar sem que as crianças sintam que o objetivo é também uma atividade educativa. O teatro consiste numa forma descontraída de levar informações, conceitos e definições voltadas para a conservação do meio ambiente. Ao mesmo tempo em que informa, também interage, diverte e ensina. 
O teatro de fantoches representa o lúdico criativo, preenchendo espaços no campo da interatividade e dinamicidade em ambientes naturais. A sensibilização ambiental é fundamental na formação conceitual infantil, aqui trata-se especificamente do teatro como estratégia para sensibilizar crianças sobre a importância de se conservar aquele local. Assim, este estudo tem no teatro de fantoches um veículo de disseminação de informações, priorizando a sensibilização da comunidade acerca da conservação da biodiversidade e do equilíbrio ambiental.

Apesar de poder ser uma ferramenta utilizada no aprendizado tanto na escola como fora dela, este trabalho demonstrou que o uso de teatro de fantoches, é uma estratégia pedagógica que pode ser usada em unidades de conservação, porque mesmo estando as crianças em um local aberto, com infinidade de atrativos, são capazes de se ater ao espaço determinado para a representação teatral e prestar atenção ao tema abordado pelo processo educativo.

\section{Breve análise dos bonecos utilizados e seus potenciais lúdicos-teatrais}

Os bonecos de luva, também conhecidos como Fantoches, é um tipo de marionete popular que marcou toda uma época e hoje é considerado um traço da cultura mundial, em destaque na cultura nordestina.

O Fantoche recebe vida por uma pessoa que coloca a sua mão dentro do boneco produzindo os seus movimentos, gestos e falas, vivificando um personagem. Geralmente o dedo indicador sustenta a cabeça do fantoche enquanto que o polegar e o anular fazem a vez dos braços. No entanto, há uma diversidade de fantoches produzidos a partir de materiais recicláveis que não nos permite especificar as características de cada um. Para tanto, analisaram-se os aspectos positivos e negativos dos bonecos de três tipos de fantoches, confeccionados a partir da técnica do Papel Machê, de E V A (Ethil Vinil Acetat) e de tecidos. Com a prática foi possível observar os seus potenciais de uso. Conforme é possível observar no Quadro 1. 
Quadro 1- Síntese das características gerais dos bonecos utilizados nas apresentações teatrais.

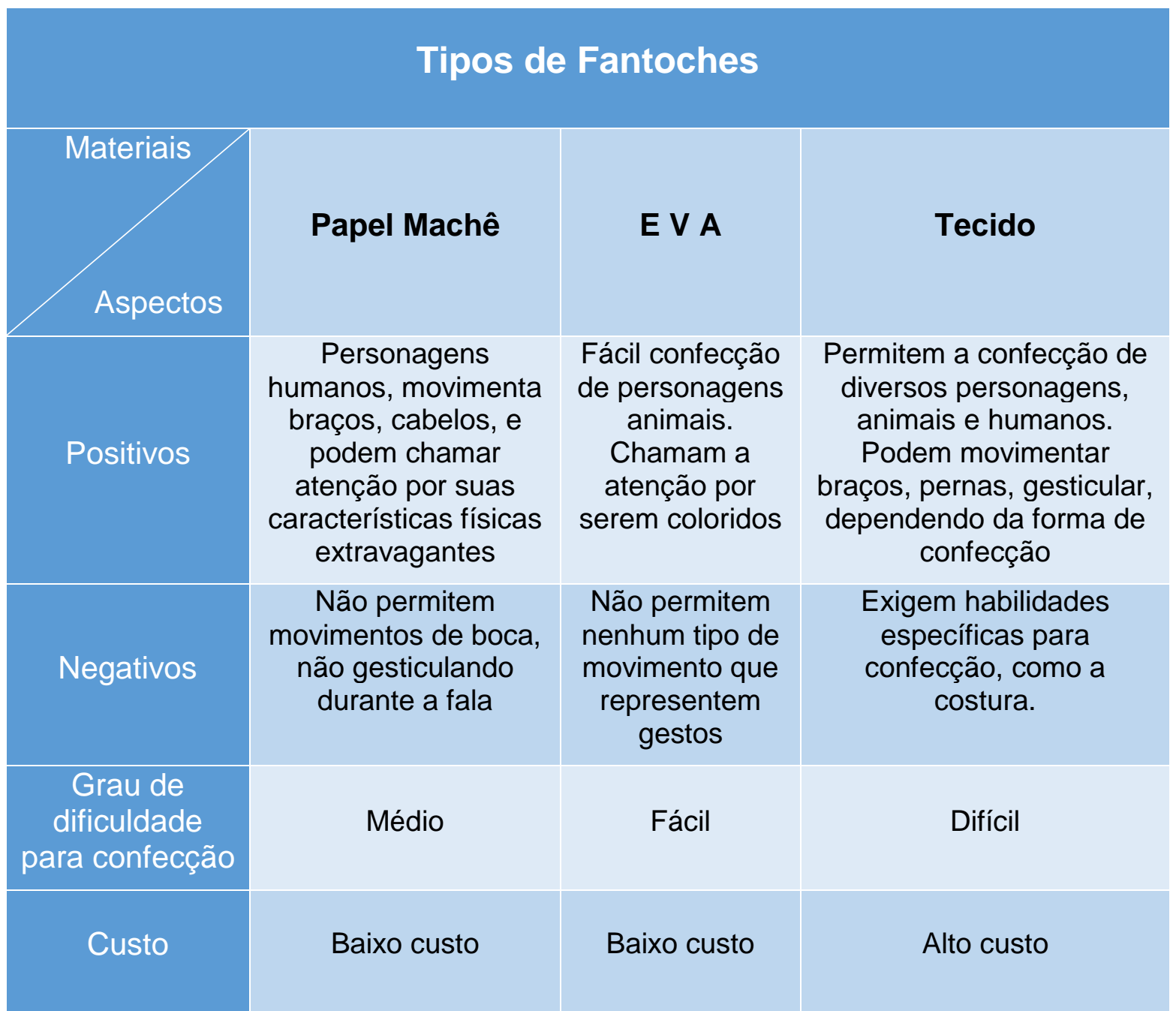

Fonte: Dados da pesquisa, 2016.

Diante do exposto, observou-se que os bonecos confeccionados a partir de materiais recicláveis são mais acessíveis em relação ao custo e ao grau de dificuldade para a sua produção. Os materiais podem ser facilmente encontrados em estabelecimentos comerciais e instituições que, por vezes, descartam de maneira inadequada. O E V A (Ethil Vinil Acetat), é um material de baixo custo e bastante utilizado em artesanato decorativo. $O$ tecido, apesar de ser reciclável, não é tão fácil de encontrar em doações e a depender do tipo seu custo é bem variável. Logo, o reaproveitamento desses materiais para a confecção de um elemento útil e lúdico já configura uma contribuição para o manejo adequado de resíduos sólidos.

Foi o que ocorreu na fase de preparação dos elementos teatraisbonecos e cenários. Foram recolhidos papel A4, plástico, papelão, canos PVC, retalhos de tecidos, entre outros materiais utilizados, em instituição pública do 
estado da Paraíba. Todo o papel utilizado na preparação da massa do papel machê foi material de descarte. Nas Fíguras 1, 2 e 3 abaixo é possível observar os produtos finais.

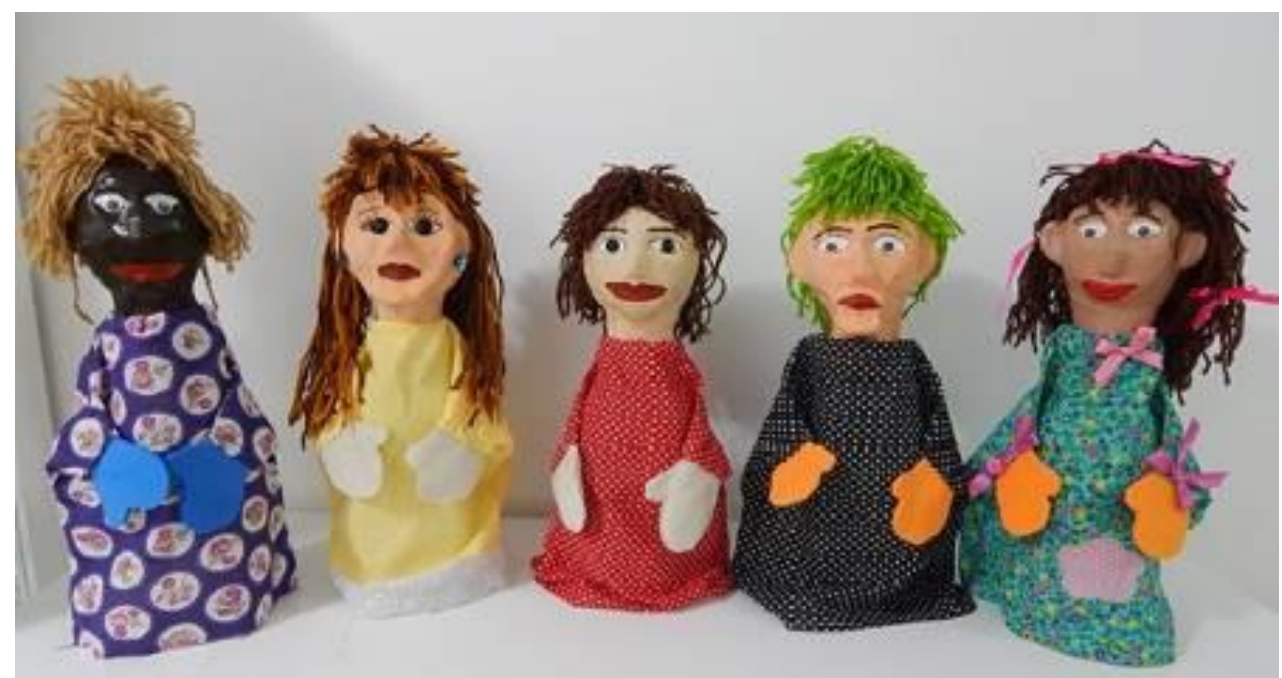

Figura 1 - Fantoches de papel machê utilizados como personagens durante as apresentações teatrais.

Fonte: Dados da pesquisa, 2016.

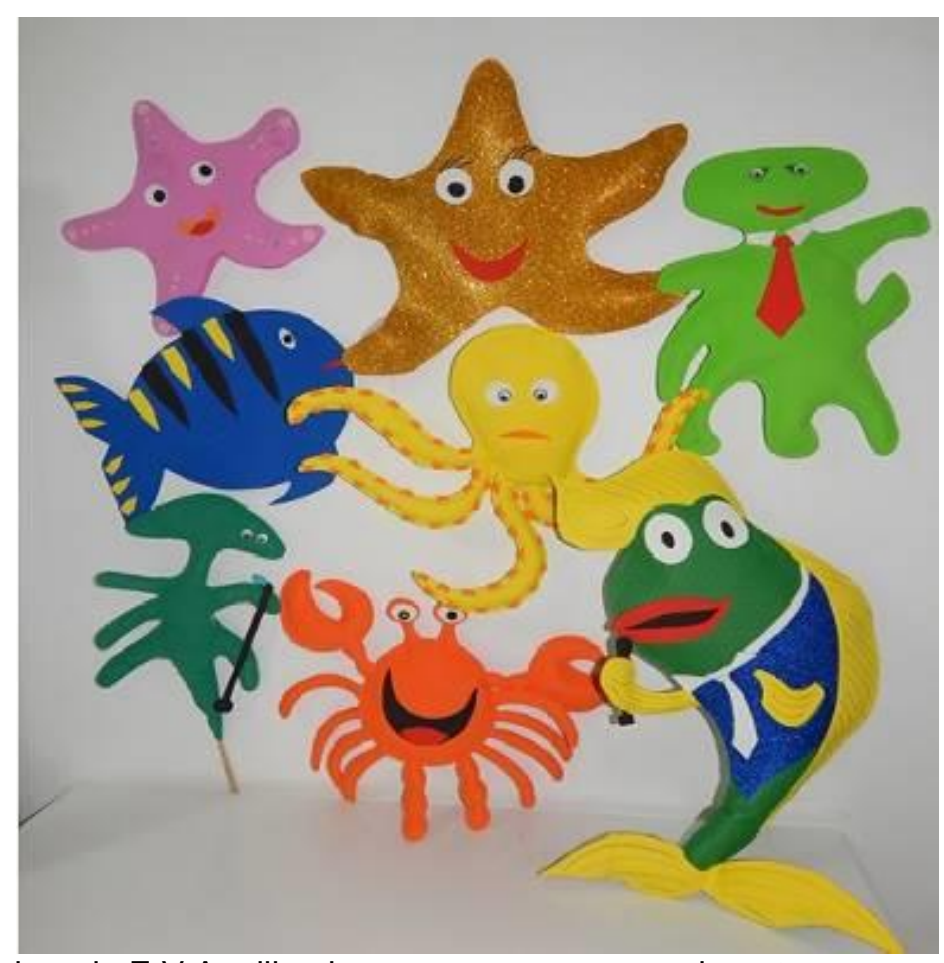

Figura 2 - Fantoches de E V A utilizados como personagens durante as apresentações teatrais Fonte: Dados da pesquisa, 2016. 


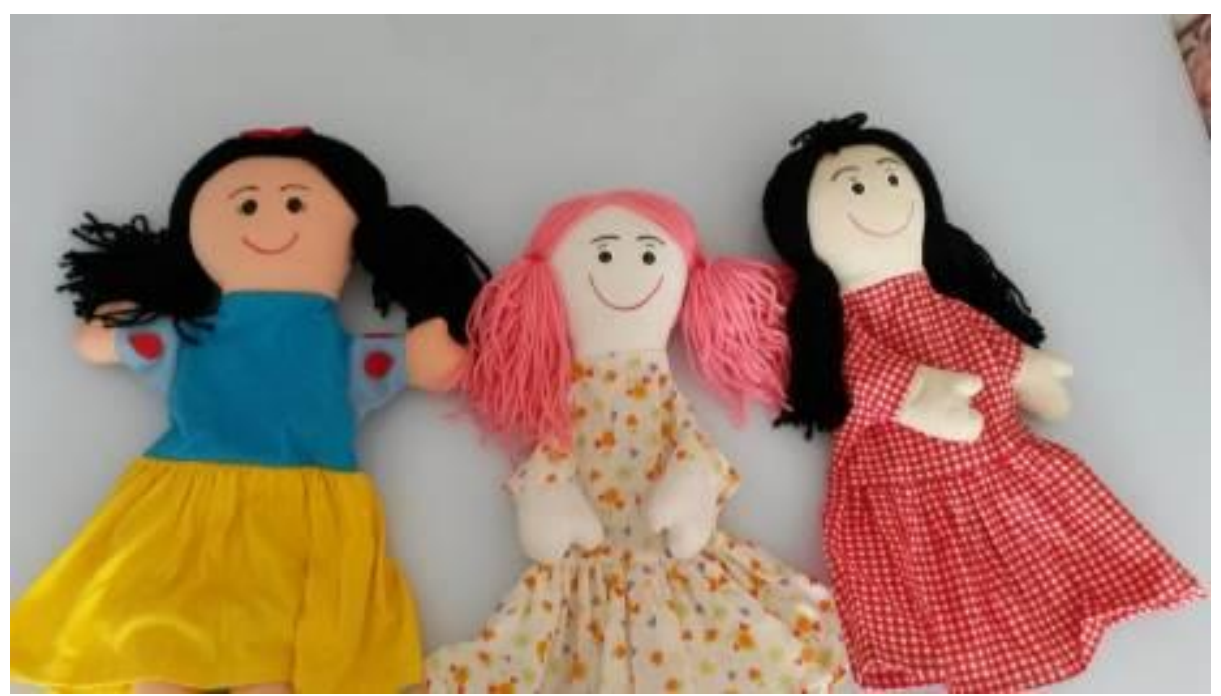

Figura 3 - Fantoches de Tecido utilizados durante as apresentações teatrais Fonte: Dados da pesquisa, 2016.

Durante o processo de confecção dos bonecos, observou-se que os bonecos de tecido são os mais complexos para serem preparados. Exigem do criador habilidades de corte e costura bem precisas. A depender dos tecidos a serem utilizados é possível conseguir doações de cortes e retalhos em casas de costura e venda de tecidos. Os bonecos de tecido apresentam infinitas possibilidades de produção, já que possuem características bastante versáteis. Tudo vai variar de acordo com a criatividade do arte-educador.

\section{Considerações Finais}

Tendo como base as experiências durante este estudo, as propostas de produção de bonecos para utilização em roteiros teatrais contextualizados com a conservação da biodiversidade, verificou-se que não existe uma receita prévia para tal. A confecção de bonecos em si, já pode configurar atividade educativa ambiental, já que se trabalha com o aproveitamento de materiais recicláveis que foram descartados. Os bonecos podem ser confeccionados para um roteiro teatral previamente selecionado, ou aleatoriamente e posteriormente ser criado um roteiro com base nos fantoches produzidos. Esta também constitui uma excelente alternativa de atividade educativa, já que estimula a criatividade e a capacidade de solucionar conflitos.

Este trabalho de Educação Ambiental com o teatro de bonecos foi realizado no Parque Estadual Marinho de Areia Vermelha (PB), uma Unidade de Conservação de Proteção integral com intensa visitação durante o verão. Foi realizada a abordagem com crianças de 07 a 12 anos, objetivou-se trabalhar o ambiente recifal, com a presença de algumas espécies marinhas e o resultado foi bastante positivo, com a integração do público na história apresentada e sua motivação para a troca de saberes e conhecimentos sobre 
temáticas como bem-estar animal, resíduos sólidos, e áreas protegidas, tudo contextualizado com a conservação dos ecossistemas.

Diante de tantas possibilidades o educador ambiental tem condições de envolver educandos com a ludicidade do teatro de bonecos e sensibilizar o público com questões realistas e desafiadoras da sustentabilidade. Num ambiente lúdico, é possível oferecer diversas temáticas ambientais que se expressam livremente através de personagens que marcam os sentidos de crianças e adultos de qualquer cultura ou meio social. Logicamente a busca por estratégias lúdicas a serem utilizadas na EA não formal não se esgota aqui, mas há o reconhecimento de que a união da ciência com a arte é sempre um bom caminho a trilhar.

O fato de usar o teatro de bonecos na educação não formal, em Unidades de conservação, não o limita a esse espaço, podendo ser igualmente aplicado na educação formal, em salas de aula ou outros espaços escolares, de acordo com a temática, número de pessoas envolvidas ou objetivo da educação proposta.

\section{Referências}

BLUMENTHAL, E. Puppetry and Puppets: An Illustrated World Survey. Thames \& Hudson Ltd. 2005.

FANTINATO, T.M; RODRIGUES, E.F. Teatro de Fantoches. PUC. 2004. Disponível em: $<$ http://pucpr.br/eventos/educere/educere2004/anaisEvento/Documentos/Cl/TC Cl019.pdf > Acesso em: 29 maio 2016.

LADEIRA, I.; CAUDAS, S. Fantoche \& CIA. São Paulo: Scipione, 1998.

PEREIRA, M.M L. Arte como processo na educação. 2. ed. Rio de Janeiro. Funarte. 2010.

POINTDARTE. $2004 . \quad$ Disponivel em: http://pointdaarte.webnode.com.br/news/a-historia-do-teatro-de-bonecos/

Acesso em: 20 jul 2016

SANTOS, D.P. Psicopedagogia dos fantoches: jogo de imaginar, construir e narrar. 1. ed. São Paulo: Vetor, 2006. 